\title{
ASSESSMENT OF SPEED-FLOW-DENSITY FUNCTIONS UNDER ADVERSE PAVEMENT CONDITION
}

\author{
J. BEN-EDIGBE \\ Department of Geotechnical and Transportation, Universiti Teknologi, Malaysia.
}

\begin{abstract}
Many of the speed, flow and density relationships postulated in different literatures are based on empirical evidences collected under favourable conditions. Those that veered into comparative analysis under contrasting conditions often use forced curves to describe the relationship between speed and flow mainly because the graph is not a function. However, the paper is an attempt to postulate that dynamic speed-flow, speed-density and flow-density functions have similar behavioural pattern. In the study, speed and flow relationship under adverse road surface condition depicted with potholes and edge subsidence among others was investigated. The study was carried out in Nigeria where adverse road surface condition on principal roads is prevalent under daylight, dry weather and off-peak conditions. It is based on the hypothesis that adverse road surface condition has significant impact on otherwise uninterrupted traffic stream. The paper compared empirical survey data from 11 locations on roadway segments with control and adverse sections. Optimum speeds for control and adverse road sections were estimated and compared. The study found $50 \%$ reduction in optimum speed and concluded that significant speed reduction will occur under adverse road surface condition.
\end{abstract}

Keywords: adverse-conditions, dynamic, speed-flow, speed-reduction.

\section{BACKGROUND}

Despite documented impacts of adverse conditions on highway traffic stream, their correlations remain tenuous. Limitations of dynamic passenger car equivalency as well as insufficient research activities are factors that may be held accountable, it can be argued. Adverse conditions such as traffic congestion, inclement weather and pavement distress among others have significant impacts on vehicle speed and traffic flow. With respect to motorist, they limit visibility, vehicle control, surfacing grip, driving comfort and also increase vehicle operating costs. In addition, they are source of extra maintenance and safety costs to road providers.

Road surfacing is made up of wearing and base courses. It enables good ride quality to be combined with the appropriate resistance to skidding, potholes, edge subsidence and vertical deflection (speed cushions, humps and speed tables). Therefore road surfaces must be free from physical defects such as potholes, loose aggregates and broken edges, rutting and cracking, failing which the quality of road service and indeed the quantity of traffic provided would be reduced significantly. Poor road surfaces are not only recipes for congestion and road accidents, they are characterised by slower speeds, longer travel times, increased queuing and severe discomfort. However, the paper is not about how pavement distresses are acquired, rather it focuses attention on vehicle volume and speed traversing such roadways.

Three primary measures namely flow, speed and density characterise the operational state of any given traffic stream. For the purpose of measuring quantity, the parameters, density and flow are important, whereas speed and flow are often relied on for measuring quality of road service. In a previous study by Ben-Edigbe $[5,14]$ where the quantity of service was measured, pavement distress was shown to reduce roadway capacity by $30 \%$ with an average speed reduction of about $50 \%$ $(20 \mathrm{~km} / \mathrm{h})$. By sharp contrast, Transport Research Laboratory or TRL investigated the influence of potholed road surfaces on vehicle speed and suggested an average speed reduction of about $6 \mathrm{~km} / \mathrm{h}$. These significant differences imply that there is a clear need for full empirical studies that will 
directly address the extent of speed reduction attributable to road pavement with significant number of potholes. In question will be the dynamic speed-flow function that has not received adequate research attention over time. Researchers still rely on Greenshield's 1934 speed-flow curve.

Whilst the speed-flow curve is adequate in describing single roadway traffic stream, it does not prescribe model equations for analytical purposes mainly because the graph is not a function. In response to the functional deficiency, pavement distress impact study was carried out in Nigeria where $81 \%$ of principal paved roads are in dire conditions. The paper presents speed-flow function based on the hypothesis that significant speed and flow reductions would result from pavement distress irrespective of how it was measured. The objectives are:

1. To measure traffic volume and speed under control condition (dry weather, daylight and good surfacing).

2. To measure traffic volume and speed under adverse condition (dry weather, daylight and distressed surfacing .

3. To analyse and compare results of both conditions.

In the light of the discussion so far, the remainder of the paper has been organised as follows: in section 2 concepts on highway traffic stream will be discussed; section 3 is on pavement distress literature; while section 4 is on research approach followed by results and analysis in section 5; findings are presented and discussed in section 6. Conclusions are drawn in the final section.

\section{HIGHWAY TRAFFIC STREAM CONCEPTS}

In UK Department of Transport - DTp advice note TA79/99 [16], capacity is defined as the maximum sustainable flow of traffic passing in 1 hour, under favourable road and traffic conditions. The advice note concluded that the capacities shown are for 'favourable 'daylight conditions. Where the road and traffic conditions are unfavourable, suitable capacity estimation methods would have to be used. The methods include estimation with headways, estimation with traffic volumes, estimation with traffic volumes and speeds and finally estimation with traffic volumes, speeds and densities. It is obvious that roadway capacity is central to traffic analysis. Fundamental relationship between speed (u), flow (q) and density (k) is the core of such analysis. In the relationship;

$$
\mathrm{q}=\mathrm{uk}
$$

\subsection{Quantitative traffic measurement}

Roadway capacity is central to speed, flow and density relationship because it captures the relationships at peak. It is time dependent and constrained by traffic and ambient and road conditions. Traffic conditions refer to the characteristics of the traffic stream and the stream components that use the facility, such as traffic composition, directional distribution, proportion of different types of vehicle and their performance capability. Ambient conditions are usually weather, visibility, level of pedestrian activity, number of parked vehicles and frontage activity among others. Road conditions include road surface and geometric parameters (number and direction of lanes, lane widths, shoulder widths, lateral clearances from edge of pavement, design speed, type of intersections and horizontal and vertical alignments). Theories of roadway capacity have sought to address the complex issues of highway capacity estimation methods. Broadly four highway capacity estimation methods (headway, traffic volume, speed/flow and flow/density) have been discussed extensively in many literatures. It can be mentioned in passing that they all have their advantages and disadvantages. All the methods 
are a mixture of observation and theory. It can be argued that some methods have more theoretical justification than others, especially those that have to contend with probabilistic functions.

The relationship between flow and density is fundamental to highway traffic quantitative analysis. But the drawback is that density would have to contend with the measurement of speed using the fundamental relationship of flow, speed and density. Nowadays, especially with advent of technology, density can be easily measured with automatic traffic counters. In any case, where density is measured and related to speed, highway capacity can be estimated. Fig. 1 shows a typical road capacity shift or so-called capacity drop, where jam density $\left(\mathrm{k}_{\mathrm{j}}\right)$ is the ultimate limit of the number of vehicles per road lane length. It cannot be exceeded. The apex $\mathrm{Q}$ is the maximum flow under prevailing critical density. It is the roadway capacity. The corresponding slopes are vehicle speeds.

In the flow-density relationships, density is the control parameter while flow is the objective function. It is governed by quadratic function. However, the function theory dictates that concavity in the flowdensity curve must have appropriate signs for validity. Therefore the coefficients signs at $\beta_{1}$ must be positive and negative at $\beta_{2}$ in order not to violate the concavity rules. If it is assumed that the straight line that represents the flow-density relationship $\left(\mathrm{k}^{2} \mathrm{k}_{0}\right)$ is tangent to the quadratic curve at critical density it can be argued that $\beta_{0}$ must also return a negative or zero sign. Hence eqn 2 can be written as:

$$
q=-\beta_{0}+\beta_{1} \mathrm{k}-\beta_{2} \mathrm{k}^{2}
$$

where $\beta_{\mathrm{o}}$ is a constant, $\beta_{1}$ and $\beta_{2}$ are model coefficients.

The drawback with this method lies with determining the critical density. It can be derived, estimated or assumed as appropriate, but how, it may be queried. It is quite possible to extrapolate mathematically till the maximum of the q-k function is reached but would such theoretical values so computed compare with the actuality of traffic operation. It may even be the case that such calculated capacities are unrealistically high and questionable. It can even be argued that capacities

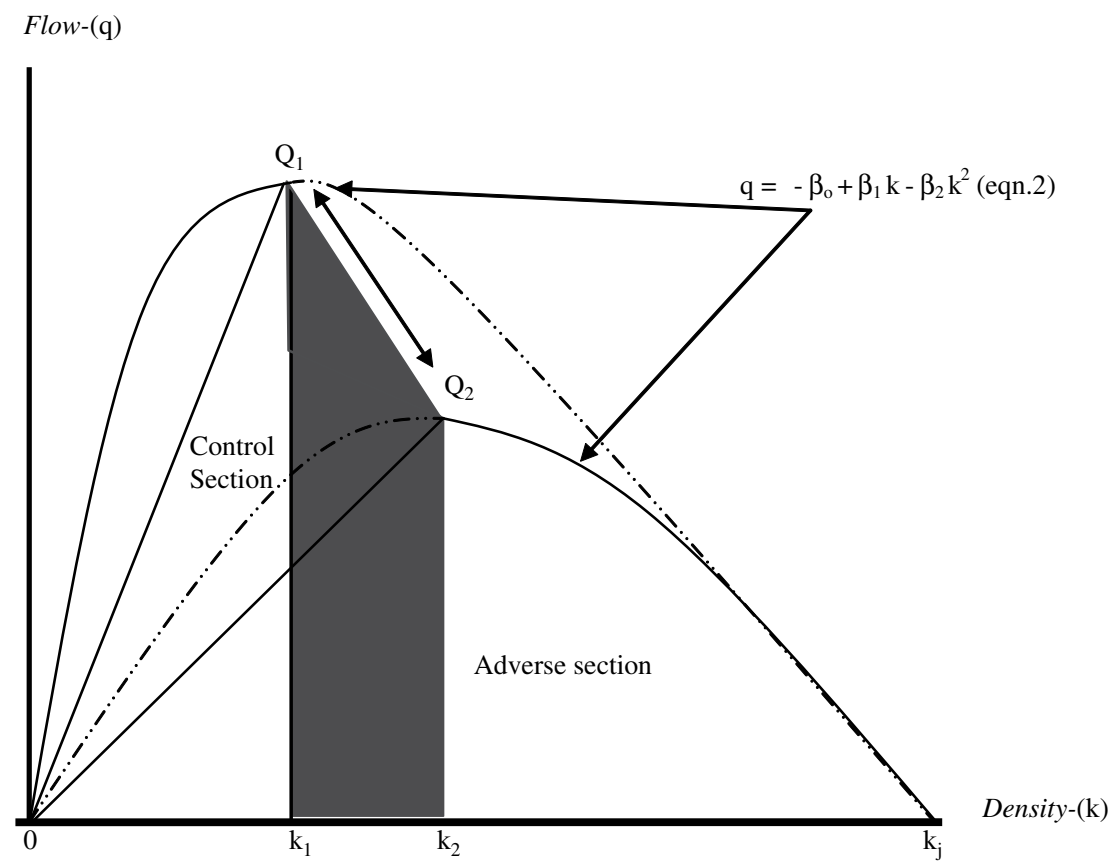

Figure 1: Hypothetical roadway capacity drop. Source: [5]. 
derived in such a way may have very little resemblance to traffic actuality. In any case, since our interest is in estimating the capacity change due to pavement distress, the choice of precise value of critical density need not be very critical to the outcome.

In Fig. 1, the control section is $0 \mathrm{Q}_{1} \mathrm{k}_{1}$ while the adverse section is $\mathrm{Q}_{2} \mathrm{k}_{2} \mathrm{k}_{\mathrm{j}}$. The slopes $0 \mathrm{Q}_{1}$ and $0 \mathrm{Q}_{2}$ represent corresponding speed. Roadway capacity loss is $\mathrm{Q}_{1}-\mathrm{Q}_{2}$. The double sided arrows indicate projected movements from control to adverse section. When condition improves $\mathrm{Q}_{2} \mathrm{k}_{2}$ is expected to move along $Q_{2} Q_{1}$ till $Q_{1} k_{1}$ is reached and vice versa. The shaded area can be computed with eqn (3). The slope $\mathrm{Q}_{1} \mathrm{Q}_{2}$ is speed, linearity is influenced by adverse section curve. Since speed-flow and speed-density have fundamental relationship as shown in eqn (1), it can be postulated that speed-density and speed-flow will also exhibit the same behavioural pattern illustrated. The area under the curve is shown as:

$$
\mathrm{A}(\mathrm{k})=\int_{\mathrm{k}_{1}}^{\mathrm{k}_{2}} \mathrm{q}_{\mathrm{m}}-\beta_{0} \mathrm{k} \partial_{\mathrm{k}}
$$

\section{$2.2 \mathrm{Speed} / \mathrm{density}$ relationship under adverse conditions}

Speed-density curve has negative linear function under 'favourable' conditions. Consider eqns (1) and (2) discussed earlier. By plugging eqn (1) into (2), speed-density equation shown about can be written as:

where constant $\beta_{0}=v_{\mathrm{f}} / \mathrm{k}_{\mathrm{j}}$.

$$
\begin{aligned}
\text { Speed, } & v=-\beta_{0} / \mathrm{k}+\beta_{1}-\beta_{2} \mathrm{k} \\
v & =v_{\mathrm{f}}-\beta_{0} \mathrm{k}
\end{aligned}
$$

But then, how will the curve respond to adverse road surface condition. Is it a case of mere point adjustments on linear functional lines, or perhaps slope oscillation between extreme points with jam density as the pivot or can we expect complete curve-shifts? Since capacity loss would result from adverse conditions as shown in Fig. 1, it follows that the resultant linear model for speed-density would also result in optimum speed loss as illustrated in Fig. 2, where the optimum speeds for control and adverse conditions are $\mathrm{u}_{1}$ and $\mathrm{u}_{2}$ respectively. With jam density serving as the pivot,

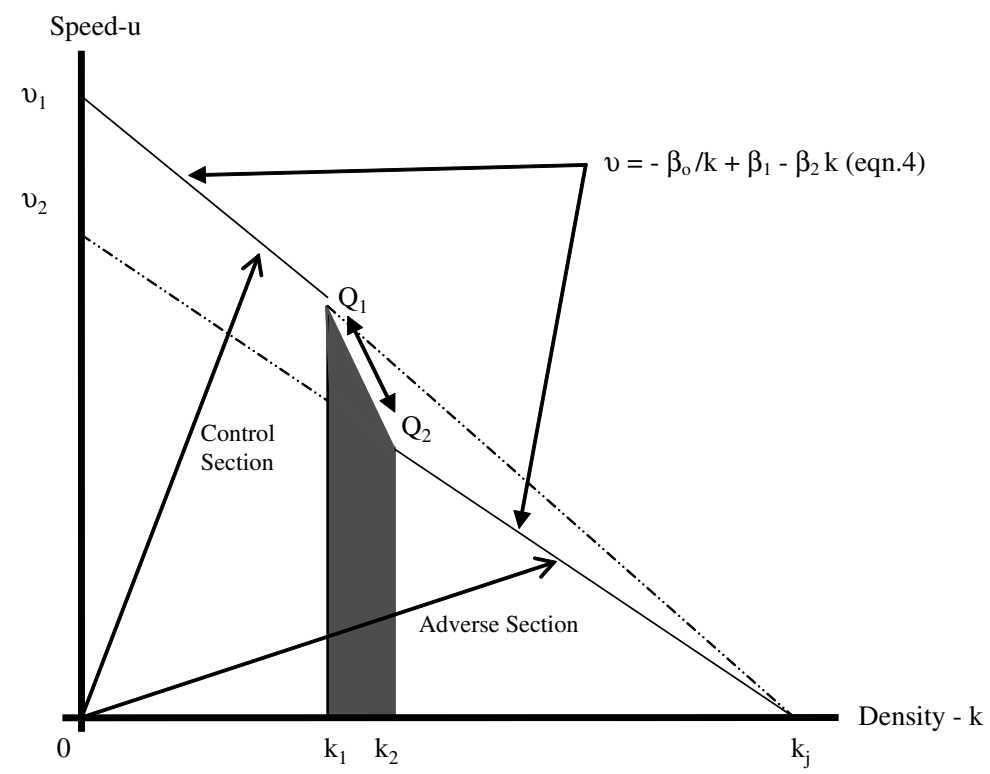

Figure 2: Hypothetical optimum speed drop. Source: [5]. 
speed can oscillate between $\mathrm{u}_{1}$ and zero depending on the prevailing condition. Where $\mathrm{u}_{1}$ and $\mathrm{u}_{2}$ are optimum speeds, $Q_{1}$ and $Q_{2}$ are corresponding roadway capacities respectively. As expected, critical densities $\mathrm{k}_{1}$ and $\mathrm{k}_{2}$ are within the control boundaries 0 and $\mathrm{k}_{\mathrm{j}}$.

In Fig. 2, the slope $=\mathrm{km}^{2} / \mathrm{Nh}$, where $\mathrm{N}$ is number of vehicles and $\mathrm{h}$ is hour. The shaded area can be computed with eqn (5). The slope linearity is influenced by adverse section curve. Since speed, flow and density have fundamental relationship, it can be postulated that speed-density also exhibit the same quadrilateral pattern similar to the one in Fig. 1. In both cases density is the control parameter. The area under the curve is given as:

$$
A(k)=\int_{k_{1}}^{k_{2}} u_{f}-\beta_{0} k \partial_{k}
$$

\subsection{Qualitative traffic measurement}

In the Highway Capacity Manual-HCM, level-of-service (LOS), which is taken as a measure-of-effectiveness, uses the letters A (best) through $\mathrm{F}$ (worst) to describe prevailing road traffic condition. According to HCM 2000 LOS E is a marginal service state where flow becomes irregular and speed varies rapidly, but rarely reaches the posted limit. On highways, this is consistent with a road operating over its designed capacity. Is HCM 2000 suggesting that LOS is based on design capacity that can be exceeded by operating capacity and at the same time suggesting that roadway capacity is defined as the maximum number of vehicles per hour that can pass a road point under prevailing circumstances? Take for example, one kilometer single carriageway lane operating at almost jam density; let's assume that road occupancy per vehicle is 5 meter; it's obvious that about 200 vehicles can be expected along the road length. If we now assume a time headway equivalent to human reaction of 2.5 seconds, the estimated roadway capacity would be 1440 vehicles per hour. It's clear cut. Improving headway to a maximum of 1.8 seconds would lead to capacity increase from 1440 to 2000 veh per hour and vice versa. Consider eqn (6):

$$
\mathrm{u}=-\beta_{0} / \mathrm{k}+\beta_{1}-\beta_{2} \mathrm{k}
$$

As $\beta_{0} / \mathrm{k}$ is small and negligible, eqn (4) can be rewritten as:

$$
\mathrm{u}=\beta_{1}-\beta_{2} \mathrm{k}
$$

where $\mathrm{k}=\mathrm{q} / \mathrm{u}$, then $\mathrm{u}^{2}=\beta_{1} \mathrm{v}-\beta_{2} \mathrm{q}$. Let, $\mathrm{q}_{\mathrm{m}}=\mathrm{u}_{\mathrm{o}} ; \beta_{2} \mathrm{v}=\mathrm{u}_{\mathrm{f}} ; \mathrm{u}_{\mathrm{f}} / \mathrm{q}_{\mathrm{m}}=\mathrm{u}_{\mathrm{f}} / \mathrm{u}_{0}=\beta_{2}$. Then eqn (6) can be written as:

$$
\mathrm{U}^{2}=\mathrm{u}_{\mathrm{f}}-\left(\mathrm{u}_{\mathrm{f}} / \mathrm{u}_{0}\right) \mathrm{q}
$$

As shown above, the equations that govern speed-flow curve do not suggest quadratic function; rather they point to a negative linearity at the upper portion of the curve and positive curvilinear at lower position of the curve below the optimum speed horizon. Eqn (6) being a negative linear function terminates at maximum flow $\left(\mathrm{q}_{\mathrm{m}}\right)$ or optimum speed $\mathrm{U}_{\mathrm{o}}$. In qualitative measurement of road service, speed is a function of flow; since eqn (7) is a negative linearity curve with maximum and optimum speeds as extreme values, it's only applicable to the uncongested portion of the speed-flow curve. Within this section, highway traffic operates in free flow mode with speed oscillating between free flow and optimum. Once optimum speed is reached at highway capacity, additional vehicles in the traffic stream will trigger a congested traffic flow mode where vehicle speeds become unpredictable, perturbation sets in, oscillation movement stops; the positive linear curve goes into a coil and recoil mode. This is depicted by the lower section of the speed-flow curve as shown in Fig. 3. In any case, should prevailing highway road surfacing conditions improve, traffic disturbances removed and optimum speed reached, the curve reverts back to the free flow optimum speed and starts to oscillate again. 
The sequence can be repeated many times especially in urban areas and city centres. Figure 4 illustrates speed-flow functions within this context. The double sided arrows indicate responsive movements of the adverse slope relative to the prevailing condition. When condition improves optimum speed $u_{02}$ tends toward $\mathrm{u}_{\mathrm{o} 1}$ with $\mathrm{q}_{2}$ approaching $\mathrm{q}_{1}$ simultaneously, till a free flow speed is reached. In essence, the slope $u_{f} Q_{1}$ determines the roadway segment capacity; when capacity is exceeded then the roadway is oversaturated and a level of service F is reached. According to TRB 2000, LOS F applies whenever the flow rate exceeds segment capacity. This postulation is absolutely correct.

The slope $0 Q_{2}$ or $\mathrm{Q}_{1} \mathrm{U}_{\mathrm{f}}=$ spacing $=\mathrm{u} / \mathrm{q}$ or hu or $\mathrm{k}^{-1}$ where $\mathrm{h}$ is headway and $\mathrm{k}$ is density. The shaded area $(\mathrm{A})$ is given by:

$$
\mathrm{A}(\mathrm{q})=\int_{\mathrm{q}_{1}}^{\mathrm{q}_{2}} \beta_{0} \mathrm{q} \partial_{\mathrm{q}}
$$

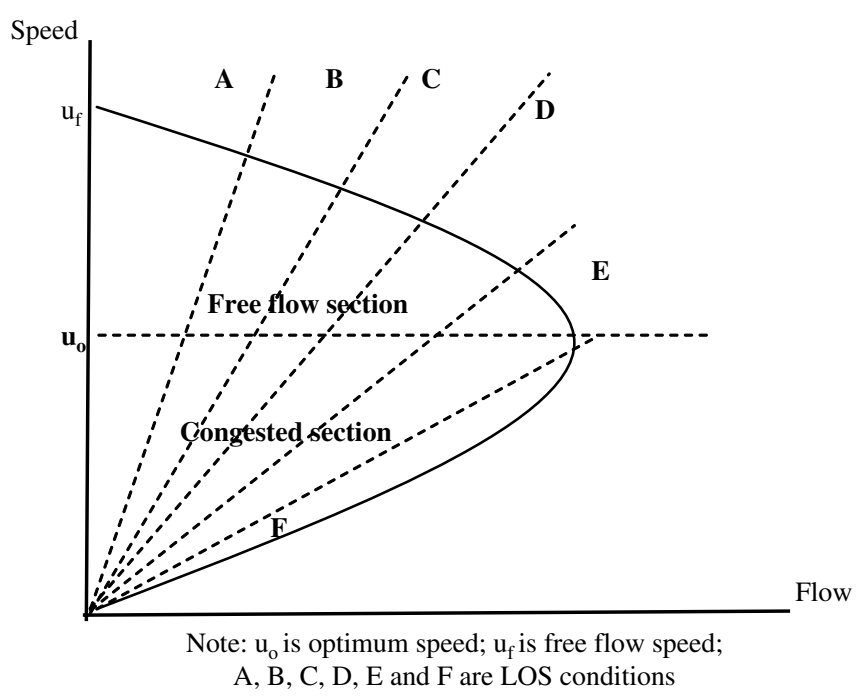

Figure 3: Typical HCM Speed-flow curve [4].

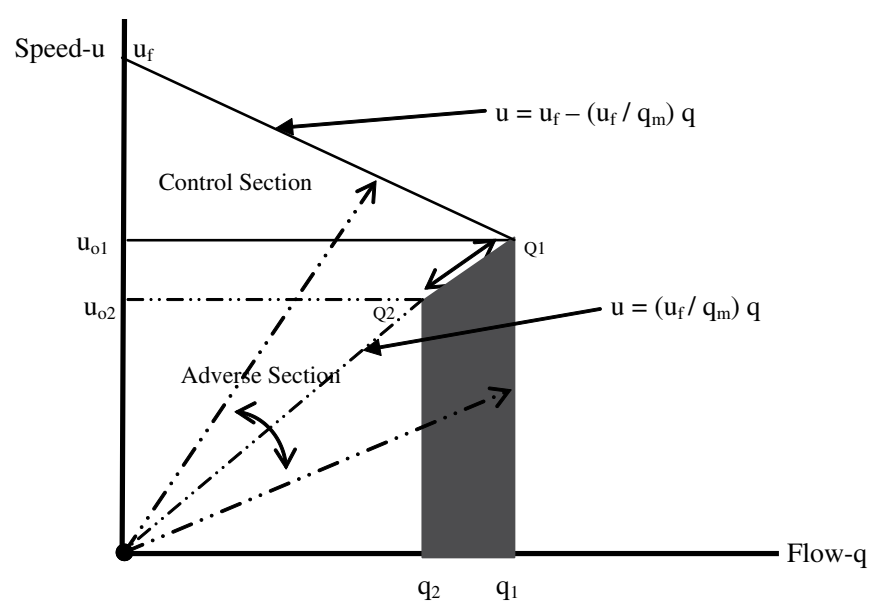

Figure 4: Hypothetical speed-fl ow curves and LOS. 
In sum, highway traffic flow can be categorized into two modes, uncongested and congested. Uncongested traffic or free flow mode depicts a highway where traffic demand is less than the capacity, vehicle speeds oscillating between optimum and free flow speed limits. Whereas congested traffic mode depicts a highway where capacity is over sub-subscribed, speeds become unpredictable, quality of service is significantly reduced, vehicles are herd and synchronised.

\subsection{Implication of adverse road surface for passenger car equivalent values}

The term 'passenger car equivalent' (PCE) is defined as 'the number of passenger cars displaced in the traffic flow by truck or a bus under the prevailing roadway, traffic and ambient conditions'. PCE values are measures of vehicle performances characterised by a variety of transport modes. Their use is central to qualitative and quantitative analysis where mixed traffic streams are present. PCE values for road sections with poor surfacing would obviously not be the same as those of the road sections with good surfacing, so care should be taken when applying these values. By applying PCE, attempts are made to determine the number of passenger cars displaced in the traffic flow by non-passenger cars such as motorcycles, light goods vehicles, buses, trucks and heavy goods vehicles under prevailing conditions. Since highway capacities vary from point to point, section to section, it can be argued that PCE values would also vary accordingly. Overtime scholars $[5,8,9,11]$ have argued about the definition and bases for numerical derivation of PCE values. In fact many researchers have tried to quantify the effect of non-passenger cars on traffic flow relying on HCM approach but using different methodologies and equivalency criteria. Some studies utilized field data, while most employed traffic simulation to derive PCEs for a wide range of conditions often with doubtful and exaggerated outcomes.

PCE values for vehicle types under poor surfacing condition have to be determined using appropriate method. In the United Kingdom, pre-determined passenger car equivalent values are usually applied to traffic volumes when converting from vehicles per hour to passenger car units per hour. The headway method is one of the several techniques for measuring PCEs. By using the headway method one is implying that the relative amount of space occupied by a vehicle in motion is the basis for calculating PCE values. Since PCE values are central to highway traffic analysis, it follows that reduction in vehicle speeds resulting from pavement distress would also have effects on the PCE values. In any case, when considering the mechanisms by which road surfacing condition may possibly influence roadway capacity, two groups of factors seem most important: the changing behaviour of drivers and the changing composition of traffic. Therefore, when computing highway capacity and by extension level of service, prevailing conditions should be taken into account and their implications reflected in computed PCE. Take note that ignoring PCE modifications or recalibration could lead to grossly inaccurate estimates with attendant consequences for transportation modelling.

\section{ROAD PAVEMENT DISTRESS}

Road deterioration can be construed as a function of original design, material types, construction quality, road geometry, pavement age, environmental conditions, maintenance policy pursed, traffic volume and axle loading. Defects are usually manifested in the form of cracking, rutting, ravelling, potholes, roughness, edge break, surface texture and polished surface. It can be argued that research into the influence of pavement distress on roadway capacity loss has not been undertaken before this study, as there are no evidences of literature on previous work. Probably the closest research works are on the road humps and speed cushions. They are usually in the form of measuring road service quality before and after installation of humps or speed cushions with attention concentrated on the level of service and road safety. It can be mentioned in passing that literatures on the influence of severe pavement distress on roadway capacity loss are scarce if at all. This may not be unconnected 
with the fact that severe pavement distress is mainly found in developing countries where research works are limited for whatever reasons. In any case, there are two distinct types of pavement distress with significant discomfort to road users, pavement disintegration and vertical deflection (speed cushions, humps and speed tables). Both have significant impacts on uninterrupted traffic flow.

Pavement distress measurements are usually taken in many literatures as percentage of affected area relative to road section with particular attention on sizes, numbers and depth. In the United Kingdom, the Department of Transport (DTp) road note advice 20/84 of 1997 suggested that for validity, carriageway lane must not be less that $2.5 \mathrm{~m}$, therefore potholes, ravelling and edge damages with transverse widths greater than $500 \mathrm{~mm}$ on a $3.1 \mathrm{~m}$ carriageway (allowing $100 \mathrm{~mm}$ for road markings) would have violated lane width tolerance level. Specifically, pothole was defined as open cavity in road surface with at least $150 \mathrm{~mm}$ diameter and at $25 \mathrm{~mm}$ depth. Pothole may also be described as any localised loss of material or depression in the surface of a pavement that compromises the ride quality of the pavement.

Given that the justification for the construction of roads is that they promote social development and economic growth, then the tests of optimising road use would call for road surfaces to be free from physical defects such as potholes, loose aggregates, and broken edges, rutting and cracking. Pavement distress is a persistent problem in many poor countries. Potholing, edge subsidence and road pavements cracking under tropical climate are problematic and are yet to be fully researched. In many developing countries, many principal roads were built on low cost road policy where very thin surfacing of about $40 \mathrm{~mm}$ is laid direct on lateritic road base. In most case the bending stress of such roads and their structural integrity are poor and the inherent failure often occurs in the very first year, although it is generally considered that roads begin to deteriorate after entering service, gradually get worse as time progresses until a failure condition is reached well beyond design life.

\section{RESEARCH APPROACH}

Study sites were divided into three sections with Section A as the upstream end and Section $\mathrm{C}$ as the downstream end, while Section B was the transition part allowing for possible congestion flow upstream of the distressed section. Section B was set at $130 \mathrm{~m}$ from the baseline of Section A and B based on eqn (9). The spacing of road sections commenced from Sections C to B where the sighting distance of motorists was first estimated using observed average free flow speed of $90 \mathrm{~km} / \mathrm{h}$ or $55 \mathrm{mph}$ taken at point A. Assuming 5\% gradient (G), 2.5 seconds reaction time (t), 0.30 coefficient of friction (f) and stopping distance (S),

$$
\mathrm{B}=0.278 \mathrm{Vt}+0.039 \mathrm{~V}^{2} / \mathrm{a}
$$

where $\mathrm{B}=$ stopping sight distance, $\mathrm{ft}(\mathrm{m}) ; \mathrm{V}=$ design speed, $\mathrm{mph}(\mathrm{km} / \mathrm{h}) ; \mathrm{t}=$ brake reaction time, $2.5 \mathrm{~s} ; \mathrm{a}=$ driver deceleration, $\mathrm{ft} / \mathrm{s}^{2}\left(\mathrm{~m} / \mathrm{s}^{2}\right)$.

Point $\mathrm{A}$ is spaced at $50 \mathrm{~m}$ from $\mathrm{B}$; and $\mathrm{B}$ is $130 \mathrm{~m}$ from $\mathrm{C}$ as illustrated in Fig. 5; note that the distribution of potholes is random and it may not necessarily follow a particular pattern. According to Department of Transport's (DTp) advice note TA 20/84 [16], the minimum width acceptable for traffic lane is $2.5 \mathrm{~m}$. Therefore, it can be postulated that any pavement distress that will reduce the width of road lane lesser than $2.5 \mathrm{~m}$ irrespective of their arrangements will affect traffic operating capacity. Data was collected from 11 sites with control and adverse section. Simple measurements

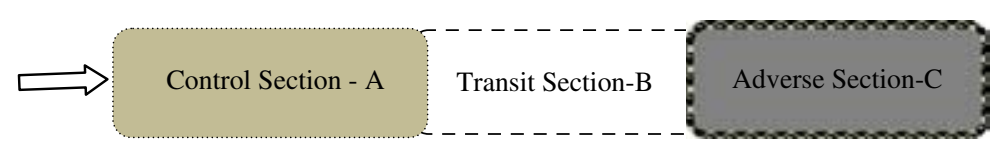

Figure 5: Roadways with pavement distress impact set up. 
are required for pavement distress as contained in most literature and they include: type of distress, length, width, depth, affected area, number (nos.) and the relative percentage of distress.

\section{RESULTS AND ANALYSIS}

The study employed a simplistic approach based on Greenshield's headway. By using the headway method one is implying that the relative amount of space occupied by a vehicle in motion is the basis for calculating PCE values. Same PCE estimation method was applied to the road section with vertical deflection for the purpose of consistency in application. From observations at survey sites, passenger cars sometimes force HGVs to slow down especially when they are platoon leaders because of their manoeuvrability difficulties on road sections with vertical deflection. These observations further validate the definition of PCE values and to some extent the reason why the PCE values of HGVs and LGVs could be slightly less than 1.0 given unfavourable conditions. It is worth noting that PCE values are dynamic and tasked with presenting the effect of mixed traffic stream for capacity and level of service analysis. Observations and further analysis revealed that passenger cars often struggle to keep pace with commercial vehicles on road with pavement distress. Traffic flows are worst when passenger cars are the platoon leaders. Thus, the problem of passenger car equivalency values in roadway capacity analysis cannot be ignored. On the one hand it shows the potential of commercial vehicles gaining control of roadway by exploiting the presence of pavement distress. On the other hand it exposes the weakness of passenger cars as mode of transport on distressed road surfaces. Notwithstanding the method adopted in estimating distressed PCE values, the effects on the outcome of the study is insignificant. Roadway capacity loss was estimated using the quadratic function and fundamental relationship between flow, speed and density. Optimum speeds were extrapolated from the computed capacities. By computing roadway capacity for each section, it is recognised that capacity varies per road section and the method used for estimating capacities is based on the fundamental relationship between flow, speed and density. Since PCE values are central to roadway capacity calculation it follows that reduction in vehicle speeds resulting from pavement distress would also have effects on the PCE values. Therefore PCE were computed for traffic flows under control and adverse conditions for consistency. Sample calculations follow:

5.1 Worked example for site J001 using headway method of calculating PCE between vehicles under saturated flow conditions as

$$
\mathrm{PCE}_{\mathrm{ij}}=\mathrm{H}_{\mathrm{ij}} / \mathrm{H}_{\mathrm{pcj}}
$$

where $\mathrm{PCE}_{\mathrm{ij}}$ is the PCE of vehicle type $\mathrm{i}$ under conditions $\mathrm{j}$, and $\mathrm{H}_{\mathrm{ij}}, \mathrm{H}_{\mathrm{pcj}}$ is the average headway for vehicle type $\mathrm{i}$ and passenger car for conditions $\mathrm{j}$.

Spacing $=1000 / 32=31.250 \mathrm{~m} / \mathrm{veh}$;

Headway $(\mathrm{PC})=31.250 / 25=1.250 \mathrm{sec} / \mathrm{veh}$;

Headway $(L G V)=31.250 / 19=1.645 \mathrm{sec} / \mathrm{veh}$;

Headway $(\mathrm{HGV})=31.250 / 16=1.953 \mathrm{sec} / \mathrm{veh}$

PCE $(\mathrm{PC})=1.0$ unit;

$\operatorname{PCE}(\mathrm{LGV})=1.645 / 1.250=1.316$ unit;

$\operatorname{PCE}(\mathrm{HGV})=1.953 / 1.250=1.563$ unit

\subsection{Steps for roadway capacity and optimum speed assessment}

Step 1: Estimate flow, speed and density using appropriate PCE values.

Step 2: Determine variances and standard errors.

Step 3: Use flow/density relationships to determine flow/density model coefficients.

Step 4: Test model equations for validity. 
Step 5: Estimate critical densities by differentiating flow with respect to density.

Step 6: Determine roadway capacities by plugging critical densities into model equations.

Step 7: Use eqn (1) to determine optimum speeds.

Step 8: Compare optimum speeds and capacities to determine speed and flow drops.

The estimated coefficient values presented in Table 1 have the expected signs. Since the focus of the paper is speed-flow reduction, a worked example of how optimum speeds were computed for both sections is shown, with the remainder results summarised in Table 2. The results for the remainder sites including peak hour factors, length of adverse section and number of potholes at adverse section are tabulated in Table 2. Road width is approximately $3.6 \mathrm{~m}$ with single carriageway. Worked example for control and adverse section at site J006 is presented here:

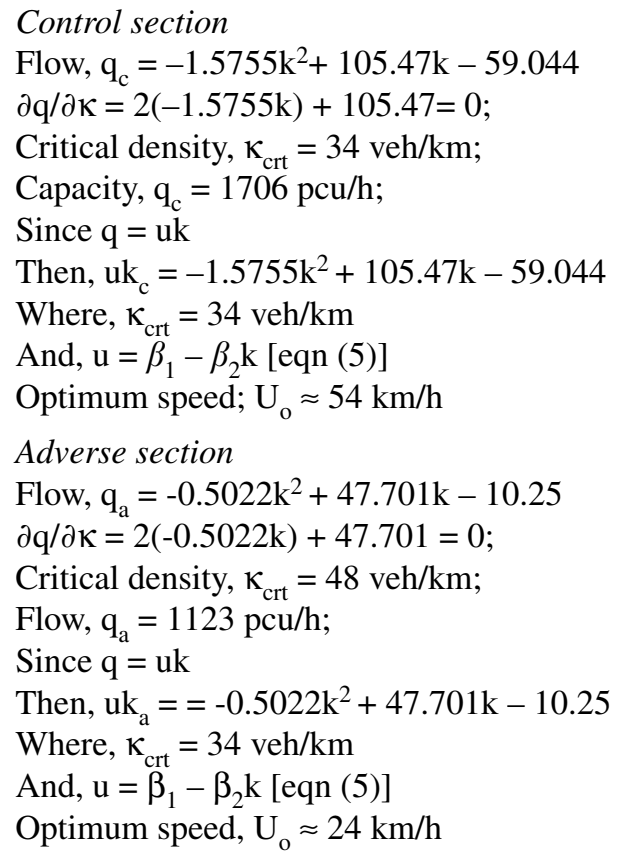

\section{FINDINGS AND DISCUSSION}

This study is based on the hypothesis that significant road service reduction would result from pavement distress. The aim behind this exercise is to establish the extent of road service reduction in the presence of pavement distress. For the purpose of estimating road capacity the quadratic relationship between flow and density in a situation of free flow was used. Two sets of PCE values (the standard and the modified values) were used. Within the purview of the study objectives, we set out two road sections: one with (adverse section) and the other without pavement distress (control section). Both sections were surveyed and the empirical results investigated.

In light of evidences obtained from the examination of survey data, the analytical findings for both road sections were compared. The empirical results from surveyed sites showed that the highest recorded volume of vehicles was at site J001 with 666 vehicles during the one-hour duration count while site J003 recorded the lowest at 483 vehicles. J001 with $262.26 \mathrm{~m}^{2}$ has the largest area of pavement distress while J009 with $22.96 \mathrm{~m}^{2}$ has the smallest pavement distress area. J008 with 17 holes has the most potholes while J005 with 5 has the least. It was observed that HGVs are least affected by pavement distress from the three type of vehicles (passenger car, light goods vehicle, heavy goods vehicle) considered in this study and it is reasonable to suggest that increase in percentage of HGVs 
Table 1: Estimated coefficients of flow-density model [eqn (2)].

\begin{tabular}{|c|c|c|c|c|c|}
\hline \multirow{2}{*}{$\frac{\text { Site }}{\text { J001 }}$} & \multicolumn{2}{|c|}{$\begin{array}{c}\text { Density } \\
-\beta_{0}\end{array}$} & \multirow{2}{*}{$\begin{array}{c}\text { Speed } \\
\beta_{1} \mathrm{k} \\
127.59\end{array}$} & \multirow{2}{*}{$\begin{array}{c}\text { Flow } \\
-\beta_{1} k^{2} \\
2.0200\end{array}$} & \multirow{2}{*}{$\frac{\mathrm{R}^{2}}{0.9822}$} \\
\hline & Control & 168.50 & & & \\
\hline & Distressed & 99.614 & 50.326 & 0.4435 & 0.9179 \\
\hline \multirow[t]{2}{*}{ J002 } & Control & 8.1055 & 123.98 & 2.2180 & 0.8724 \\
\hline & Distressed & 39.438 & 50.260 & 0.5079 & 0.9668 \\
\hline \multirow[t]{2}{*}{ J003 } & Control & 8.1055 & 101.28 & 2.2922 & 0.9578 \\
\hline & Distressed & 143.15 & 63.795 & 1.0255 & 0.9792 \\
\hline \multirow[t]{2}{*}{ J004 } & Control & 99.337 & 113.35 & 1.8229 & 0.9782 \\
\hline & Distressed & 186.32 & 59.133 & 0.5283 & 0.9744 \\
\hline \multirow[t]{2}{*}{ J005 } & Control & 100.07 & 109.00 & 1.8194 & 0.9757 \\
\hline & Distressed & 17.473 & 49.646 & 0.5088 & 0.9269 \\
\hline \multirow[t]{2}{*}{ J006 } & Control & 59.044 & 105.47 & 1.5755 & 0.9601 \\
\hline & Distressed & 10.250 & 47.701 & 0.5022 & 0.9520 \\
\hline \multirow[t]{2}{*}{ J007 } & Control & 59.545 & 112.42 & 1.7820 & 0.9673 \\
\hline & Distressed & 63.593 & 49.815 & 0.4928 & 0.9487 \\
\hline \multirow[t]{2}{*}{ J008 } & Control & 109.47 & 128.760 & 2.4825 & 0.9839 \\
\hline & Distressed & 85.221 & 51.792 & 0.5045 & 0.9951 \\
\hline \multirow[t]{2}{*}{ J009 } & Control & 58.054 & 108.030 & 1.8220 & 0.9920 \\
\hline & Distressed & 49.719 & 48.046 & 0.4696 & 0.9559 \\
\hline \multirow[t]{2}{*}{ J010 } & Control & 25.826 & 109.660 & 1.4786 & 0.9132 \\
\hline & Distressed & 38.603 & 53.886 & 0.4431 & 0.8602 \\
\hline \multirow[t]{2}{*}{ J011 } & Control & 69.403 & 113.27 & 1.6822 & 0.9299 \\
\hline & Distressed & 151.96 & 55.218 & 0.5066 & 0.9810 \\
\hline
\end{tabular}

Table 2: Highway capacity and speed reduction.

\begin{tabular}{|c|c|c|c|c|c|c|c|c|c|c|c|c|c|c|}
\hline \multirow[b]{2}{*}{ Site } & \multicolumn{5}{|c|}{ Control section } & \multicolumn{7}{|c|}{ Adverse section } & \multicolumn{2}{|c|}{$\begin{array}{l}\text { Speed } \\
\text { reduction }\end{array}$} \\
\hline & PHF & $\mathrm{u}_{\mathrm{o}}$ & $\mathrm{k}_{\mathrm{c}}$ & $\mathrm{Q}$ & LOS & $\begin{array}{l}\text { Length } \\
\text { (m) }\end{array}$ & $\begin{array}{c}\mathrm{PH} \\
\text { (nos) }\end{array}$ & PHF & $\mathrm{u}_{\mathrm{o}}$ & $\mathrm{k}_{\mathrm{c}}$ & $\mathrm{Q}$ & LOS & $\mathrm{km} / \mathrm{h}$ & $\%$ \\
\hline J001 & 0.69 & 57 & 32 & 1824 & $\mathrm{C}$ & 86.3 & 15 & 0.65 & 23 & 57 & 1311 & $\mathrm{E}$ & 34 & 0.60 \\
\hline J002 & 0.60 & 48 & 28 & 1344 & $\mathrm{C}$ & 44.5 & 13 & 0.51 & 24 & 50 & 1200 & E & 24 & 0.50 \\
\hline J003 & 0.58 & 50 & 22 & 1100 & $\mathrm{C}$ & 48.8 & 7 & 0.73 & 28 & 31 & 868 & $\mathrm{E}$ & 22 & 0.44 \\
\hline J004 & 0.69 & 53 & 31 & 1643 & $\mathrm{C}$ & 71.9 & 9 & 0.62 & 26 & 56 & 1456 & $\mathrm{E}$ & 27 & 0.51 \\
\hline J005 & 0.60 & 51 & 30 & 1530 & $\mathrm{C}$ & 53.4 & 11 & 0.63 & 25 & 49 & 1225 & $\mathrm{E}$ & 26 & 0.51 \\
\hline J006 & 0.47 & 54 & 34 & 1836 & $\mathrm{C}$ & 40.0 & 17 & 0.58 & 24 & 48 & 1152 & $\mathrm{E}$ & 30 & 0.56 \\
\hline J007 & 0.62 & 53 & 32 & 1696 & $\mathrm{C}$ & 64.4 & 15 & 0.79 & 23 & 51 & 1173 & $\mathrm{E}$ & 30 & 0.57 \\
\hline J008 & 0.76 & 53 & 26 & 1378 & $\mathrm{C}$ & 46.4 & 12 & 0.54 & 25 & 51 & 1275 & $\mathrm{E}$ & 28 & 0.53 \\
\hline J009 & 0.44 & 60 & 30 & 1800 & $\mathrm{C}$ & 27.7 & 14 & 0.55 & 23 & 51 & 1173 & $\mathrm{E}$ & 37 & 0.62 \\
\hline J010 & 0.45 & 51 & 37 & 1887 & $\mathrm{C}$ & 27.3 & 16 & 0.54 & 25 & 61 & 1525 & E & 26 & 0.51 \\
\hline J011 & 0.56 & 54 & 34 & 1836 & $\mathrm{C}$ & 54.4 & 13 & 0.76 & 23 & 55 & 1265 & $\mathrm{E}$ & 31 & 0.57 \\
\hline
\end{tabular}

Source: [5].

Note: $\mathrm{PH}=$ potholes, $\mathrm{PHF}=$ peak hour factor, critical density $=\mathrm{k}_{\mathrm{c}}$, optimum speed $=\mathrm{u}_{\mathrm{o}}$, capacity $\mathrm{Q}=\mathrm{u}_{\mathrm{o}} \mathrm{k}_{\mathrm{c}}$, LOS $=$ level of service (TRB 2000). 
may affect the extent of road capacity loss. From the study it was found that site J004 has the lowest relative pavement distress area of $134 \mathrm{~m}^{2}$ while site $\mathrm{J} 006$ has the highest relative pavement distress area of $219 \mathrm{~m}^{2}$. Site J005 has the least number of potholes (7) while site J008 has the highest (17). Optimum speed loss of $48 \%$ resulted from $125 \mathrm{~m}^{2}$ relative pavement distress in the presence of 15 potholes at Road J001. At J008 the optimum speed of $41 \%$ resulted from $161 \mathrm{~m}^{2}$ relative pavement distress in the presence of 17 potholes. The optimum speed loss of 20 percent at site J005 resulted from $149 \mathrm{~m}^{2}$ relative pavement distress area, given 7 potholes. Interestingly, even though site J006 had the second lowest optimum speed of $25 \%$ with the second lowest level of pavement distress, the sites had the largest proportion of commercial vehicle suggesting that commercial vehicles suffer less from pavement distress when compared to passenger cars and should be an area for further research. The fact that commercial vehicles with high axle clearance from road surface are extremely turn-around time sensitive hence more liable to be driven aggressively irrespective of road condition cannot be discounted. Nevertheless, all types of vehicles will suffer in the long run as road conditions continue to deteriorate. In sum the study showed that:

1. Significant road service reduction would result from pavement distress.

2. Computed PCE values were lower than the standard PCE values.

3. Linear relationship exists between speed and flow.

4. Pothole is a significant contributor to road service reduction.

Consider Fig. 6a for site J001, $\mathrm{U}_{\mathrm{f}}-\mathrm{Uo}_{1}$ line represents control speed-flow function, 0 - $\mathrm{Uo}_{2}$ line represents adverse speed-flow function. $U_{01}-U_{02}=$ speed reduction for this site. Spacing ( $(\mathrm{s}) \mathrm{m} / \mathrm{veh}=\mathrm{u} / \mathrm{q}$; therefore empirical spacing for control and adverse sections are 63 and $17 \mathrm{~m} / \mathrm{veh}$ respectively. $\mathrm{Q}_{2} \mathrm{U}_{02}$ tends toward $\mathrm{Q}_{1} \mathrm{U}_{01}$ as condition improves or moves away as condition deteriorates further. This behavioural pattern is repeated in findings from the remaining sites. Moreover, from observations at surveyed sites, trucks are less affected by pavement distress than passenger cars and it may be argued that the passenger car equivalent values of trucks or HGVs are somewhat lower than or same as those of passenger cars. It can be mentioned in passing that there was a sharp difference in the attitude of heavy goods vehicle drivers on road section with surfacing distress. HGV motorists pay very little attention to pavement distress as observed at surveyed sites. It may be argued that because of change in drivers' attitude relative to pavement distress, description that depicts passenger car equivalency value for $\mathrm{HGV}$ as substantially higher than one unit on distressed level terrain is somehow blurring.

In Fig. $6 b$ hypothetical speed curve has been interpolated with an optimum flow $u_{o}$, free-flow $u_{f}$ and roadway capacity $2200 \mathrm{veh} / \mathrm{h}$. The underlining assumption is that all motorists are law abiding, so typical speed limit value of $110 \mathrm{~km} / \mathrm{h}$ for free-flow, and $30 \mathrm{~km} / \mathrm{h}$ for optimum flow were employed. Interestingly, the adverse section remains below the optimum line, although the control section is slightly outside the curve, should flow increase, it will drop inside the curve. It is suggested that by applying this modelling technique, speed-flow linearity can be estimated. Analysis and findings from the study lead to the following conclusions:

- There is a significant change in level of road service between the control and adverse sections during off-peak, daylight and dry weather conditions. The finding means that there are no other factors than road pavement distress that can be held accountable for the road service reduction.

- Contrary to the nonfunctional graphs often presented in many papers, speed-flow functions are achievable by splitting the curve into two and analysing the sections separately as shown in Fig. 6 .

- Road pavement distress results in a significant optimum speed reduction from $u_{\mathrm{o} 1}$ to $\mathrm{u}_{\mathrm{o} 2}$ with an estimated $50 \%$ reduction.

- The upper portion of the speed-flow curve has negative linear function. 


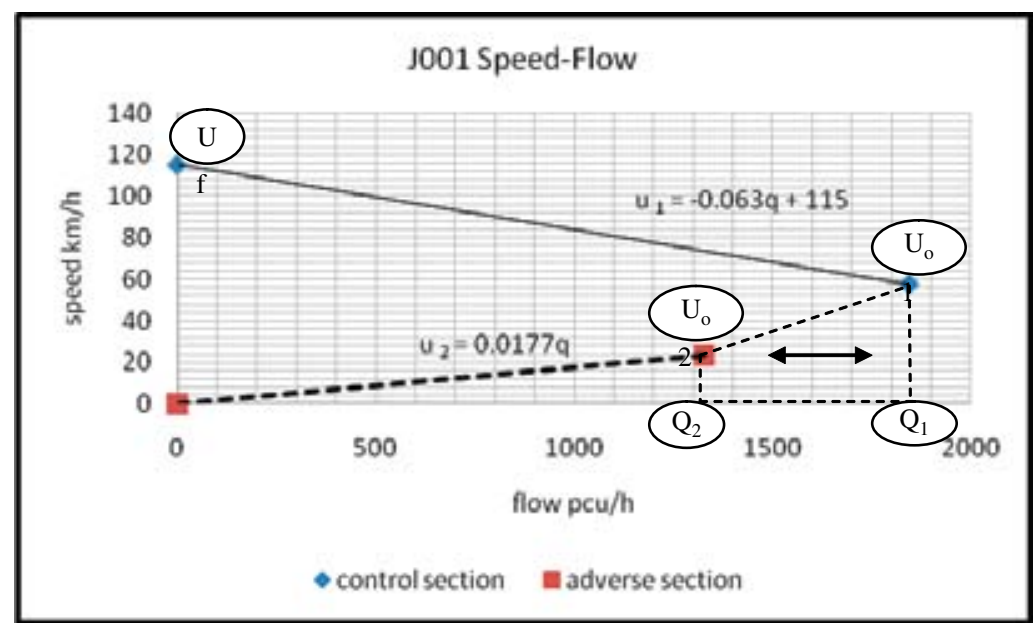

(a)

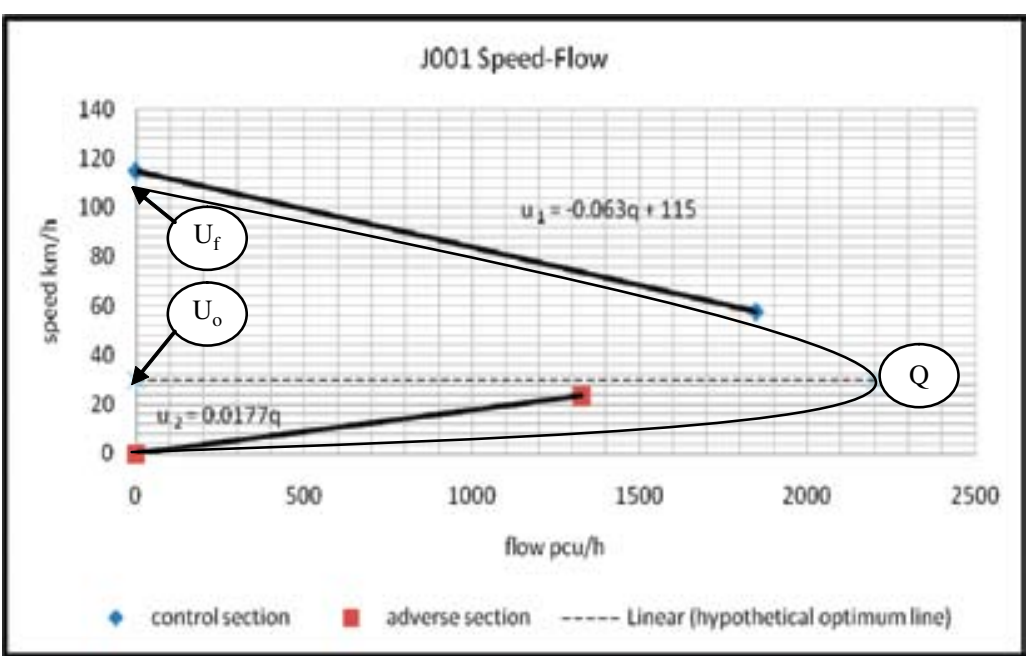

(b)

Figure 6: Typical estimated speed-flow curves for control and adverse sections. (a) Optimum speed drop resulting from adverse condition. (b) Speed-flow linearity relative to speed-flow curve.

- The lower portion of the speed-flow graph has positive linear function.

- That adverse maximum flow would move along $\mathrm{Q}_{2} \mathrm{Q}_{1}$ line as shown in Fig. 6a.

- Given that speed is normally distributed, the intersection at $\mathrm{Q}$ need not be at an angle but a curve.

- Since the probability of roadway reaching capacity at optimum speed is 1 , it can be argued that LOS E must terminate at $\mathrm{Q}$ in order not to violate probability rules.

- At the optimum speed, it may necessary to introduce LOS E2 as the adverse speed variance below the optimum line and LOS E1 above the optimum line, thereafter LOS F.

- Speed distribution fluctuates on control section, suggesting that drivers are not constrained by surface distress hence can choose speed and passing manoeuvres. Whereas on adverse section, speed distribution is almost flat suggesting that drivers were constrained by poor road surface condition. 
It is apparent from the investigations that the effectiveness of road traffic was constrained by pavement distresses. Under poor road conditions average vehicle speeds were lower than the optimum speed, drivers experienced more delays, and platoon became intense, vehicle overtaking virtually impossible and vehicle sometime travel at snail speeds. Although the paper discussed speed, flow and density relationships, the main thrust is at speed-flow polynomial functions. It would have been difficult to leave out the fundamental relationship when computing speed and flow variables because optimum speed is notoriously difficult to compute accurately.

\section{CONCLUSIONS}

Based on the synthesis of empirical evidences from the impact study, the paper has shown that:

- Speed, flow and density relationship is useful for determining speed-flow model;

- Adverse conditions have significant impact on level of road service;

- Passenger car equivalent values are dynamic;

- Negative and positive linear portions of speed/flow curves behave differently; under congestion the curve exhibit reversible shrinkage and under free flow it oscillates with optimum speed as pivot point;

- Significant reduction in speed by up to $50 \%$ would result from adverse road surface condition;

- Significant reduction in traffic flow by up to $20 \%$ would result from adverse road surface condition.

The paper has shown that speed-flow functions can be estimated by separating the curve into free flow and congested sections and applying appropriate polynomial function. At the present time a small scale study on adverse conditions and highway traffic is ongoing; notwithstanding, it would useful to conduct large scale studies on speed-flow polynomial functions. By conducting such studies, speed-flow polynomial functions presented in the paper would be tested for limitations and reliability.

\section{REFERENCES}

[1] Addison, J.D. \& Heydecker, B.G., Modelling traffic with variable speed limits. UTSG Conference, Southampton University, 2008.

[2] Balakrishna, R., Koutsopoulos, H.N. \& Ben-Akiva, M., Calibration and validation of dynamic traffic assignment systems. Proceedings of the 16th International Symposium on Transportation and Traffic Theory, Elsevier, pp. 407-426, 2005.

[3] Gurusinghe, G.S., Nakatsuji, T., Tanaboriboon, Y. \& Suzuki, J., A car-following model incorporating excess critical speed concept. Journal of Eastern Asia Society for Transportation Studies, 4(2), pp. 171-183, 2001.

[4] Transportation Research Board, National Research Council, Highway Capacity Manual 47, HCM: Washington DC, 2000.

[5] Ben-Edigbe, J.E., Influence of Pavement Distress on Road Capacity and their Implications for PCE Values, PhD Thesis, University of Strathclyde, Microfilm Library: Glasgow, Scotland, 2002.

[6] Elefteriadou, L., et al., Development of Passenger Car Equivalents for Freeways, Two-Lane Highways and Arterials, Pennsylvania transportation Institute 201 Research Office Building, University Park PA, 1998.

[7] Kerner, B.S., Three-phase traffic theory and highway capacity. Physical A: Statistical and Theoretical Physics, 333, pp. 379-440, 2004. doi:10.1016/j.physa.2003.10.017

[8] Laval, J.A. \& Leclercq, L., Microscopic modelling of the relaxation phenomenon using a macroscopic lane-changing model. Transportation Research B, 42(2008), pp. 511-522, 2007. 
[9] Ngoduy, D., Hoogendoorn, S.P. \& Van Zuylen, H.J., Comparison of numerical schemes for macroscopic traffic flow models. Transportation Research Record, (1876), pp. 52-61, 2004.

[10] Notley, S.O., Bourne, N. \& Taylor, N.B., Speeds and Flows on Motorways, TRL Report in preparation. Crowthorne House, 2008.

[11] Seguin, E.L., Crowley, K.W. \& Zweig, W.D., Passenger Car Equivalents on Urban Freeways. Interim Report, contract DTFH61-C00100, Institute for Research (IR), State College, Pennsylvania, 1998.

[12] Taylor, N.B. \& Dumbuya, A., Prospects for continuous origin- destination matrix estimation. Proc. ITS World Congress, London, 2006.

[13] Taylor, N.B., Zijpp N. van der, Zhang, X., White, C., \& Beale, S., Origin-destination matrix estimation for the Advanced Traffic Management project. Proc. Road Traffic, Information and Control Conference, 2004.

[14] Ben-Edigbe, J.E. \& Ferguson, N.S., 'Qualitative road service reduction resulting from pavement distress', WIT International Conference on Urban Transport, Bologna, Italy, 2009.

[15] Zhang, H.M. \& Kim, T., A car-following theory for multiphase vehicular traffic flow. Transportation Research Part B, 39(5), pp. 385-399, 2005. doi:10.1016/j.trb.2004.06.005

[16] UK Departmental Standards and Advice Notes in The Design Manual for Roads and Bridges TA 79/99, Traffic Capacity of Urban Roads [Amendment No. 1 ( May 1999)]. 